\title{
On penetration of IFKhAN-80 migrating corrosion inhibitor into cement stone
}

\author{
N. N. Andreev, D. S. Bulgakov, I. A. Gedvillo, A. S. Zhmakina, \\ and S. S.Vesely
}

A. N. Frumkin Institute of Physical Chemistry and Electrochemistry, Russian Academy of Sciences, Leninskii pr. 31, Moscow, 119071 Russian Federation

E-mail: n.andreev@mail.ru

\begin{abstract}
The penetration of IFKhAN-80 migrating corrosion inhibitor into cement stone was studied. It was found that the depth of steel reinforcement protection in concrete containing $3 \% \mathrm{NaCl}$ (with respect to the binder) depends on the inhibitor dosage and application method and can be up to $15-20 \mathrm{~cm}$. For practical use, the consumption rate of IFKhAN- 80 will depend on the reinforcement depth but should not be lower than $0.6 \mathrm{~L} / \mathrm{m}^{2}$.
\end{abstract}

Key words: corrosion inhibitors, migrating corrosion inhibitors, corrosion in concrete, reinforced concrete.

Received: September 1, 2014.

doi: $\underline{10.17675 / 2305-6894-2014-3-4-238-245}$

\section{Introduction}

Inhibitors are very important for the protection of metals from corrosion [1-3]. They are widely used to protect reinforced concrete structures. Along with conventional contact inhibitors introduced into concrete with tempering water, so-called migrating corrosion inhibitors (MCIs) have recently come into use. When applied to the concrete surface, MCIs penetrate into the bulk of concrete down to the steel reinforcement, thus inhibiting its corrosion [4-9].

Recently, a research team at the Frumkin Institute of Physical Chemistry and Electrochemistry of the Russian Academy of Sciences (Moscow, Russia) has developed the migrating corrosion inhibitor IFKhAN-80. This is a $30 \%$ aqueous solution of a nonvolatile corrosion inhibitor modified with a specially selected surfactant to enhance its capillary suction into cement stone pores [9].

Using indirect methods, we have demonstrated that IFKhAN-80 can migrate into the bulk of concrete to a depth of $10-12 \mathrm{~cm}$, thus ensuring the protection of the steel reinforcement. The penetration depth and rate of this inhibitor in cement stone have not yet been measured directly, nor has its protective concentration in chloride-containing concrete been determined, although these characteristics are of fundamental importance for the development of specifications concerning the MCI application. The goal of this study was to fill this gap. 


\section{Experimental}

In the first step of this study, we estimated the protective concentration of IFKhAN-80 in chloride-containing concrete $(3 \% \mathrm{NaCl}$ with respect to the binder). This chloride percentage exceeding the values commonly encountered when MCIs are used was chosen for estimating the protection limits of IFKhAN-80. Obviously, if metal protection from chloride corrosion is ensured under these conditions, the inhibitor will certainly be efficient at lower chloride concentrations.

For corrosion tests, we prepared small beam specimens $(40 \times 40 \times 160 \mathrm{~mm})$ from a chloride-containing cement-sand mixture and wire reinforcing bars (St3ps steel) completely embedded in the resulting concrete. Portland cement PTs 500 D0, sand screened through a sieve with $2 \mathrm{~mm}$ meshes, and water were mixed in a ratio of $1: 2: 0.4$. The steel bars were $6.5 \mathrm{~mm}$ in diameter and $100 \mathrm{~mm}$ long. Prior to being grouted, the steel bars were polished with emery paper and degreased with ethanol. Sodium chloride and IFKhAN-80 $(3,1.5,0.75$, or 0.375 mass $\%$ of the MCI active ingredient with respect to the binder) were added with tempering water to test specimens.

The specimens were allowed to cure indoors for seven days, then exposed in a chamber at $100 \%$ humidity for six months and at $75 \%$ humidity for an additional six months. After the entire exposure time, the concrete was partially cleaved off to examine the steel surface. The absence of corrosion centers on it was indicative of complete protection of the metal with the inhibitor in all steps of preparation and corrosion testing of the specimens.

To estimate the depth and kinetics of penetration of IFKhAN-80 into cement stone, we made cylindrical castings (diameter $0.9 \mathrm{~cm}$, length $20 \mathrm{~cm}$ ) laterally framed with Plexiglas. For this purpose, we mixed Portland cement PTs 500 D0 with water in a ratio $1: 0.4(\mathrm{~m} / \mathrm{m})$. The resulting grout was placed in Plexiglas tubes and left for indoor curing for 30 days. Then the end faces of the castings were ground with emery paper. The castings were weighed and dried in a desiccator over calcined $\mathrm{CaCl}_{2}$, while checking their mass once every month. After their mass remained constant, the castings were considered ready for kinetics studies.

We carried out tests of two types. In Type I tests, the castings were immersed on one end into a working solution of IFKhAN-80 to a depth of $1 \mathrm{~cm}$ and mounted nearly vertically in Erlenmeyer flasks. The castings were periodically withdrawn from the flasks, blotted with filter paper, and weighed. The amount of the MCI solution absorbed by the castings was evaluated from their mass gain. One, two, six, and thirteen days after the start of the test, three castings were withdrawn each time from the MCI solution and sawed into five parts of equal length $(4 \mathrm{~cm})$. The plastic casing was removed, and the resulting cement specimens were weighed and again dried in a desiccator to a constant mass. The water content in these specimens was calculated. Then the cement was ground up, stirred for $24 \mathrm{~h}$ with water $(20 \mathrm{~mL})$ on magnetic stirrers, and filtered off. The water extracts were analyzed for inhibitor content. 
In Type II tests, the castings were mounted vertically, and a working solution of MCI was applied to their top faces in the following amounts: $600,1200,2400$, or $4800 \mathrm{ml} / \mathrm{m}^{2}$. After six days, the castings were sawed into five parts and analyzed for the content of the inhibitor as described above.

\section{Results and Discussion}

The corrosion tests revealed intense corrosion of the steel bars in concrete specimens containing no IFKhAN-80 or its small amount $(0.375 \%)$. This was evident from large pits of the steel surface observed after the test and concrete removal. Larger amounts of the inhibitor $(0.75,1.5$, and $3 \%)$ ensured complete protection of the steel reinforcement because no visible traces of corrosion were detected. The minimum amount of the inhibitor required to protect the steel reinforcement from chloride corrosion was thus estimated at 0.56 mass $\%$ of the binder; this value is a midpoint in the concentration range between complete protection of the metal and lack of protection.

At the beginning of a Type I test, cement castings intensely absorbed an IFKhAN-80 solution. During the first day, their average mass gain was $0.34 \mathrm{~g}$; in three days, their mass gain was $1.19 \mathrm{~g}$. After that, the absorption rate decreased. In six, eight, and thirteen days, the mass gains were $1.42,1.66$, and $1.81 \mathrm{~g}$, respectively. A fraction of water was absorbed by the castings irreversibly when they were kept under capillary infiltration conditions for a long period of time ( 6 or 13 days). In these cases, the total water content determined from the mass losses of the cement specimens upon desiccation is appreciably lower than the content of water absorbed by the castings from the IFKhAN-80 solution (Table 1). These differences can hardly be attributed to mass losses due to the sawing of the specimens.

The water distribution along the castings was nonuniform. The highest water content was found in cement stone specimens prepared from the lower parts of the castings, which had been in contact with an MCI solution. Thus, the mass loss upon desiccation showed that the specimens $1-3 \mathrm{~cm}$ distant from the solution meniscus contained $0.12-0.15 \mathrm{~g}$ of water, this amount remaining virtually unchanged throughout the test.

For the specimens 3-7 cm distant from the meniscus and exposed to the inhibitor solution for the same period of time (1-13 days), the water content increased with time by a factor of about three and, by day 6 of the test, reached the values comparable with those of the lower specimens. This is due to slow diffusion of water across cement so that the capillaries of the specimen become filled with water.

A similar pattern was observed for the specimens $7-11 \mathrm{~cm}$ distant from the meniscus. By day 6 of the test, their water content was $0.13 \mathrm{~g}$, which seems to correspond to cement saturation with water (by day 13 of the test, the water content increased only slightly (to $0.15 \mathrm{~g})$ ).

The water content in the specimens $11-15 \mathrm{~cm}$ distant from the MCI solution was nearly equal $(0.03-0.04 \mathrm{~g})$ and did not change since the first days of the test. The same trend is characteristic of the most distant cement specimens $(15-19 \mathrm{~cm})$. Their water content was nearly equal but no higher than $0.005 \mathrm{~g}$. 
Table 1. Contents of water and the inhibitor in cement specimens in Type I tests.

\begin{tabular}{|c|c|c|c|c|}
\hline $\begin{array}{l}\text { Distance between } \\
\text { the specimen } \\
\text { and the MCI } \\
\text { solution } \\
\text { meniscus, cm }\end{array}$ & $\begin{array}{l}\text { Content of water } \\
\text { reversibly } \\
\text { adsorbed by } \\
\text { the specimen, } g\end{array}$ & $\begin{array}{l}\text { Absolute content } \\
\text { of the inhibitor } \\
\text { in the specimen, } g\end{array}$ & $\begin{array}{l}\text { Inhibitor content } \\
\text { in the water } \\
\text { reversibly } \\
\text { adsorbed by the } \\
\text { specimen, mass\% }\end{array}$ & $\begin{array}{c}\text { Inhibitor content } \\
\text { in the specimen, } \\
\text { mass } \% \\
\text { of the binder }\end{array}$ \\
\hline \multicolumn{5}{|c|}{ Test duration $24 \mathrm{~h}$} \\
\hline$(-1)-3$ & 0.148 & 0.130 & 46.8 & 3.0 \\
\hline $3-7$ & 0.055 & 0.121 & 68.8 & 3.3 \\
\hline $7-11$ & 0.057 & 0.064 & 52.9 & 1.6 \\
\hline $11-15$ & 0.041 & 0.055 & 57.3 & 1.4 \\
\hline $15-19$ & 0.003 & 0.019 & 90.5 & 0.5 \\
\hline \multicolumn{5}{|c|}{ Test duration $48 \mathrm{~h}$} \\
\hline$(-1)-3$ & 0.118 & 0.116 & 49.6 & 2.5 \\
\hline $3-7$ & 0.065 & 0.096 & 59.6 & 2.3 \\
\hline $7-11$ & 0.043 & 0.082 & 65.6 & 1.9 \\
\hline $11-15$ & 0.033 & 0.045 & 57.7 & 0.9 \\
\hline $15-19$ & 0.004 & 0.025 & 86.2 & 0.7 \\
\hline \multicolumn{5}{|c|}{ Test duration 6 days } \\
\hline$(-1)-3$ & 0.135 & 0.187 & 59.9 & 4.5 \\
\hline $3-7$ & 0.132 & 0.145 & 52.3 & 3.5 \\
\hline $7-11$ & 0.128 & 0.092 & 41.8 & 2.2 \\
\hline $11-15$ & 0.045 & 0.059 & 56.7 & 1.4 \\
\hline $15-19$ & 0.005 & 0.031 & 86.1 & 0.7 \\
\hline \multicolumn{5}{|c|}{ Test duration 13 days } \\
\hline$(-1)-3$ & 0.142 & 0.108 & 43.2 & 2.7 \\
\hline $3-7$ & 0.158 & 0.073 & 31.6 & 1.7 \\
\hline $7-11$ & 0.158 & 0.055 & 25.8 & 1.3 \\
\hline $11-15$ & 0.034 & 0.036 & 51.4 & 0.9 \\
\hline $15-19$ & 0.004 & 0.025 & 86.2 & 0.6 \\
\hline
\end{tabular}

Thus, the specimens $7-11 \mathrm{~cm}$ distant from the solution meniscus were saturated with water during the test, the saturation being completed in about six days. Apparently, the system reached a near-equilibrium state over this period of time. Some deviations from this state can be associated with water evaporation from the top face of the concrete casting and 
a compensating capillary suction of the solution of MCI from the flask. The considerable height of the capillary rise of the MCI solution is due to the presence of a surfactant among its constituents [6].

The inhibitor is absorbed, together with water, by cement stone. Analysis of the data obtained shows that the solution does not become depleted of the inhibitor as capillary suction proceeds. In contrast, the content of IFKhAN-80 in the pore solution in most cases exceeded its concentration in the initial solution. This is due to irreversible binding of water and its evaporation from the end faces of the castings. At least, enrichment of the pore solution with the inhibitor was most pronounced in the top specimens, where evaporation was very intense. The inhibitor concentration in these specimens (formally calculated from the content of water and IFKhAN-80 in them) was up to $90 \%$, regardless of the times of exposure of the castings to the solution. It should be noted that this value is far above the solubility of IFKhAN-80 in water ( $c a .35 \%)$. One can assume that the inhibitor partially precipitates from solution to accumulate in the cement stone pores in solid state or by fitting into its structure.

The content of IFKhAN-80 with respect to cement varied widely from specimen to specimen (from 0.5 to $4.5 \%$ ). This content depends only slightly on the time of exposure of the castings to capillary infiltration conditions, yet appreciably decreased as the distance between the specimen and the meniscus of the MCI solution increased. For the specimens in contact with the solution, the content of IFKhAN-80 varied from 2.5 to $4.5 \%$, while for the fragments of the casting that were most distant from the meniscus, the content was $0.5-0.7 \%$. It should be emphasized that for all the specimens closer than $15 \mathrm{~cm}$ from the IFKhAN-80 solution, this value exceeds its protective concentration determined from the corrosion data.

Therefore, for cement stone in which the content of $\mathrm{NaCl}$ is no higher than $3 \%$ of the binder mass, the protection depth provided by IFKhAN-80 under the conditions of constant capillary infiltration can reach $15-20 \mathrm{~cm}$. These conditions occur where, e.g., the surfaces of concrete floors, roofs, etc. are treated by pouring a solution of an MCI over such surfaces. The consumption rate of IFKhAN-80 calculated from the amount of its solution absorbed in $24 \mathrm{~h}$ will be $5.5 \mathrm{~L} / \mathrm{m}^{2}$. This conclusion somewhat changes the concept of the MCI application technology. First, the protection depth substantially exceeds the values claimed in the specifications of MCIs by various manufacturers. Second, the consumption rates are appreciably higher than $0.3-0.6 \mathrm{~L} / \mathrm{m}^{2}$ as usually recommended by manufacturers.

However, the conditions simulated by Type I tests may differ largely from real conditions, where an MCI applied to the concrete surface is partially adsorbed and partially evaporates. To simulate this situation and determine the consumption rates of the inhibitor and the protection depth, we carried out Type II tests. The results obtained are given in Table 2.

The tabulated data suggest that the inhibitor is reversibly adsorbed by cement stone. In all the tests, the analytically calculated total amount of the inhibitor in the casting was close to its content in solution applied to the castings. 
Table 2. Content of the inhibitor in cement specimens in Type II tests.

\begin{tabular}{|c|c|c|}
\hline $\begin{array}{l}\text { Distance between } \\
\text { the specimen and the top face } \\
\text { of the casting, } \mathrm{cm}\end{array}$ & $\begin{array}{l}\text { Absolute content of the } \\
\text { inhibitor in the specimen, } g\end{array}$ & $\begin{array}{l}\text { Content of the inhibitor in the } \\
\text { specimen, mass } \% \text { of the binder }\end{array}$ \\
\hline \multicolumn{3}{|c|}{ Inhibitor consumption rate $0.6 \mathrm{~L} / \mathrm{m}^{2}$} \\
\hline $0-4$ & 0.007 & 0.21 \\
\hline $4-8$ & 0.003 & 0.08 \\
\hline $8-12$ & $<0.001$ & $<0.02$ \\
\hline $12-16$ & $<0.001$ & $<0.02$ \\
\hline $16-20$ & $<0.001$ & $<0.02$ \\
\hline \multicolumn{3}{|c|}{ Inhibitor consumption rate $1.2 \mathrm{~L} / \mathrm{m}^{2}$} \\
\hline $0-4$ & 0.018 & 0.57 \\
\hline $4-8$ & 0.004 & 0.12 \\
\hline $8-12$ & $<0.001$ & $<0.02$ \\
\hline $12-16$ & $<0.001$ & $<0.02$ \\
\hline $16-20$ & $<0.001$ & $<0.02$ \\
\hline \multicolumn{3}{|c|}{ Inhibitor consumption rate $2.4 \mathrm{~L} / \mathrm{m}^{2}$} \\
\hline $0-4$ & 0.029 & 0.83 \\
\hline $4-8$ & 0.011 & 0.29 \\
\hline $8-12$ & $<0.001$ & $<0.02$ \\
\hline $12-16$ & $<0.001$ & $<0.02$ \\
\hline $16-20$ & $<0.001$ & $<0.02$ \\
\hline \multicolumn{3}{|c|}{ Inhibitor consumption rate $4.8 \mathrm{~L} / \mathrm{m}^{2}$} \\
\hline $0-4$ & 0.046 & 1.46 \\
\hline $4-8$ & 0.039 & 1.01 \\
\hline $8-12$ & 0.002 & 0.05 \\
\hline $12-16$ & $<0.001$ & $<0.02$ \\
\hline $16-20$ & $<0.001$ & $<0.02$ \\
\hline
\end{tabular}

In the entire range of the consumption rates studied $\left(0.6-4.8 \mathrm{~L} / \mathrm{m}^{2}\right)$, the inhibitor accumulated in the top $4-8 \mathrm{~cm}$ of the casting. At longer distances $(>8 \mathrm{~cm})$ from the top face of the casting, only trace amounts of the MCI were detected.

With an increase in the consumption rate of IFKhAN-80, its absolute content in upper specimens increased appreciably. At consumption rates of $0.6,1.2,2.4$, and $4.8 \mathrm{~L} / \mathrm{m}^{2}$, the content of the inhibitor in the upper specimen was $0.007,0.018,0.029$, and $0.018 \mathrm{~g}$, 
respectively. For specimens $4-8 \mathrm{~cm}$ distant from the top face of the original casting, the content of the inhibitor was $0.003,0.004,0.011$, and $0.039 \mathrm{~g}$ for the same consumption rates of IFKhAN-80.

The content of the inhibitor with respect to the binder in the specimens changed in a similar way. It is significant that the protective concentrations of the MCI in the specimens for the given chloride content of cement were achieved only when the consumption rate of IFKhAN-80 was above $1.2 \mathrm{~L} / \mathrm{m}^{2}$. At a consumption rate of IFKhAN-80 of $0.6 \mathrm{~L} / \mathrm{m}^{2}$, the protection of steel bars in cement stone was ensured at a depth of $<4 \mathrm{~cm}$. ${ }^{1}$ The protection depth was about $4 \mathrm{~cm}$ at $1.2 \mathrm{~L} / \mathrm{m}^{2}$ and exceeded $8 \mathrm{~cm}$ only at a consumption rate of $4.8 \mathrm{~L} / \mathrm{m}^{2}$. Therefore, when choosing the MCI consumption rate for practical applications, one should take the reinforcement depth into consideration. We recommend that the consumption rate be no lower than $0.6-1.2 \mathrm{~L} / \mathrm{m}^{2}$.

\section{Conclusions}

1. IFKhAN-80 efficiently protects steel reinforcement when added to chloride-containing concrete with tempering water. At 3\% chloride content with respect to the binder, the protective concentration of IFKhAN-80 is within 0.37 to $0.75 \%$ (based on its active ingredient).

2. IFKhAN-80 is well absorbed by cement stone under constant capillary infiltration conditions. The protection depth can be up to $15-20 \mathrm{~cm}$.

3. For practical applications, the consumption rate of IFKhAN-80 should be chosen with allowance for the reinforcement depth. The recommended consumption rate is no lower than $0.6-1.2 \mathrm{~L} / \mathrm{m}^{2}$.

\section{References}

1. Yu. I. Kuznetsov, Int. J. Corros. Scale Inhib., 2012, 1, no. 1, 3. doi: 10.17675/23056894-2012-1-1-003-015

2. N. N. Andreev, N. G. Anufriev and I. S. Sivokon, Int. J. Corros. Scale Inhib., 2013, 2, no. 1, 17. doi: $10.17675 / 2305-6894-2013-2-1-017-029$

3. A. Frignani, C. Monticelli, F. Zucchi and G. Trabanelli, Int. J. Corros. Scale Inhib., 2014, 3, no. 2, 105. doi: 10.17675/2305-6894-2014-3-2-105-119

4. B. Miksic, L. Gelner, D. Bjegovic and L. Sipos, 9th Eur. Symp. on Corrosion Inhibitors, Ferrara, 2000, vol. 1, 569.

5. J. Tritthart, Cem. Concr. Res., 2003, 33, 829.

6. N. N. Andreev, E. V. Starovoitova, I. A. Gedvillo and A. S. Zhmakina, Eurocorr-2010, Moscow, 2010, 303.

\footnotetext{
${ }^{1}$ According to [8], this depth exceeds $2 \mathrm{~cm}$ (the distance between the surface of a concrete beam specimen and its reinforcing bar).
} 
7. E. V. Starovoitova, N. N. Andreev, I. A. Gedvillo and A. S. Zhmakina, Korroz.: Mater. Zashch., 2008, no. 10, 22 (in Russian).

8. N. N. Andreev, I. A. Gedvillo, A. S. Zhmakina, T. L. Zimina, V. F. Stepanova and L. P. Kharitonova, Prakt. Protivokorroz. Zashch., 2014, no. 1, 14 (in Russian).

9. E. V. Starovoitova, N. N. Andreev, I. A. Gedvillo and A. S. Zhmakina, Korroz.: Mater. Zashch., 2008, 10, 22 (in Russian). 